\title{
Strategic Human Resource Management and Corporate Performance
}

\author{
Xiao Wang \\ Jinan University, Guangdong, China \\ Email: xiaotu940217@126.com
}

How to cite this paper: Wang, X. (2019) Strategic Human Resource Management and Corporate Performance Modern Economy, 10, 311-333.

https://doi.org/10.4236/me.2019.101021

Received: October 29, 2018

Accepted: January 20, 2019

Published: January 23, 2019

Copyright $\odot 2019$ by author(s) and Scientific Research Publishing Inc. This work is licensed under the Creative Commons Attribution International License (CC BY 4.0).

http://creativecommons.org/licenses/by/4.0/

\begin{abstract}
It is essential for success to build an organization filled with good, talented, well-trained people, which is also the center of human resource management. The author combined the complex network with human capital to solve the problems. The author employed fuzzy synthetic evaluation method to figure out the Euclidean distance between different departments in ICM, and then built the human capital network of various departments. Based on the Lyapunov stability theory, the author described the dynamic process of human capital in ICM. Through establishing the dynamic complex network model of human capital, the author drew the conclusion that the next two years' budget of recruiting and training is $34.22 \sigma$ when the annual churn rate goes to $18 \%$. By Pajek programming, the author used the visualization tools to simulate the staff flow. Through establishing the dynamic simulation model of the staff turnover, the author reached the position's integrity condition of ICM when the job churn rate is $25 \%$ and $35 \%$, respectively. Then the author explained the costs caused by high turnover rates and the indirect effects of high churn rates. The author simulated the change of position's integrity degree of junior managers and experienced supervisors in the next two years. The author concluded that the HR health of the organization is below the expectation. In addition, the author made sensitivity analysis on the 7 factors of human capital value and consequently drew that the amount of employees of each hierarchy has the greatest influence on human capital value. At last, to make further discussion on the model, the author established the multilayer complex network model including flow, trust, influence and friendship.
\end{abstract}

\section{Keywords}

Human Resource Management, ICM, Corporate Performance, Dynamic Complex Network, Fuzzy Synthetic Evaluation 


\section{Introduction}

In 2005 the European Commission (2005) explicitly stated that "well developed human resources in $\mathrm{R} \& \mathrm{D}$ are the cornerstone of advancement in scientific knowledge, technological progress, enhancing the quality of life, ensuring the welfare of European citizens and contributing to Europe's competitiveness". This acknowledgement derives from already existing EU research policies. With the coming of information and knowledge period, human capital is dominating the direction and process of the company. Therefore, there is a problem to be solved. How can we ensure the steady accumulation of human capital in the continuous development of the company? The accumulation of human capital can be done in two ways. On the one hand, each person's intelligence and skills will improve in economic activities without the pressure of production. On the other hand, we can accumulate the human capital through learning-by-doing in work, attending training courses, having foreign exchange learning. In contemporary society, when employees take part in the company, plenty of companies will use the second way to improve their skills. So how do we manage human capital in organizations?

By acknowledging this situation, more and more scholars study human capital through the following four aspects. With regular and random networks being considered, an agent model has been introduced to investigate the influence of the agents' social network [1]. By overcoming the traditional fragmentation of specific research field, the case of the Theme Teams has been analyzed to develop the researchers' human capital [2]. A brief overview of human capital research that summarizes its evolution and current areas of emphasis has been first demonstrated [3]. Consequently, it is necessary to generalize "traditional" network theory by developing a frame work and associated tools to study multilayer systems in a comprehensive fashion [4].

We find no empirical analysis of the relationship for human capital and multilayer networks. However, we can study the relationship between them from the following four aspects.

1) We need to calculate the human capital of each department in ICM. And through the objective link of human capital, we can establish the network model based on the human capital.

2) Based on Question one, we need to establish a mathematical model to describe the dynamic process of human capital network. The dynamic process consists of organizational churn and direct and indirect effects on the organization's productivity. Next, we analyze our organization's budget requirements for talent management in terms of $\sigma$ for both recruiting and training over the next 2 years through the dynamic model.

3) By using the dynamic model in Question two, we can study whether ICM can sustain position's integrity rate of $80 \%$ or not when the annual churn rate for all positions reaches $25 \%$ ? How about churn rate of $35 \%$ ? And we analyze the costs of these higher turnover rates and the indirect effects caused by these high 
churn rates.

4) We should simulate the impact on the junior managers and experienced supervisors when churn rate arrives at $30 \%$. And then we have to explain the impact of the HR health condition of the organization in that situation to the ICM HR supervisor.

\section{The Overall Analysis of the Problem}

Building an organization filled with good, talented, well-trained people is one of the keys to success. In order to achieve this, an organization not only needs to recruit and hire the best candidates, but also they need to retain good people, keep them properly trained and place them in proper positions, and eventually target new hires to replace those leaving the organization. All members in the team play a specific role. Therefore, the departure of individuals from an organization leaves important informational and functional components missing that need to be replaced.

Through analysis, we can know that there is an objective link among employees. So we can construct a complex network model to study the impact on the entire complex relationship network system of ICM when staff turnover occurs. What's more, we can take advantage of large complex network analysis tool to dynamically analyze and deal with the whole complex network model. And we can eventually give advice to the human resource management of ICM.

At last, we show our research ideas through this flow chart (Figure 1).

\section{Symbol Descriptions (Table 1)}

Table 1. Variables and definitions.

\begin{tabular}{ccc}
\hline Number & Parameter & Meaning \\
2 & $a$ & Total cost of company's paying for employees \\
3 & $b$ & The value of the employees' returning to the company \\
4 & $n_{i j}$ & The amount of employees of the $j$ department within $i$ floor \\
5 & $m$ & Median time to recruit (months) \\
6 & $A s$ & Average annual salary rate for given lever \\
8 & $M c$ & Median cost of recruitment \\
9 & $A t$ & Average annual training cost \\
10 & $\alpha_{i j}$ & Employees' satisfaction rate of the $j$ department within $i$ floor \\
11 & $\delta$ & The satisfaction rate of the company \\
\end{tabular}

Chart source: organize by the author.

\section{Human Capital Network Model of ICM Organization}

\subsection{The VP Branch to Demonstrate the Complex Network}

For question one, to make it easier to demonstrate the method of building a 


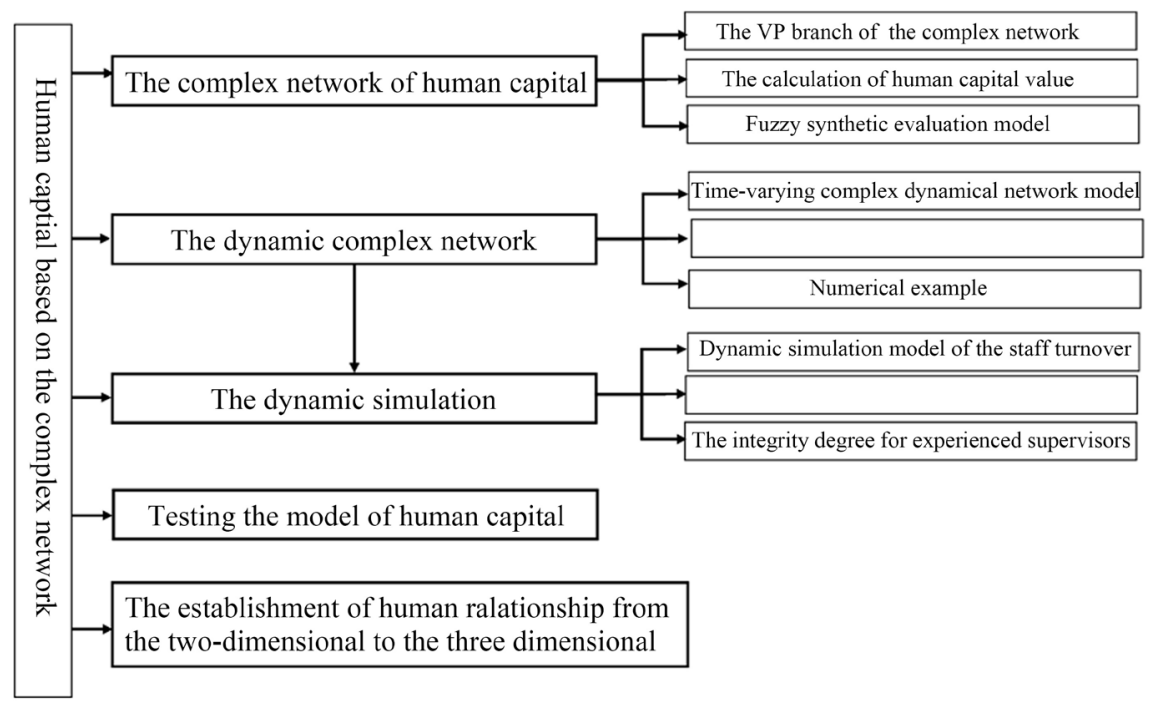

Figure 1. The flow chart of the analysis of problems. Chart source: organize by the author.

complex network, we select a branch of ICM including each level department as an example, so that we can analyze the general situation of human capital network in ICM. We define the total cost of company's paying for employees, average annual salary rate of employees and the value of the employees' returning to the company, and then we build their interrelationships to calculate the human capital value.

\subsection{The Calculation of Each Department's Human Capital Value}

\subsubsection{Definition of the Human Capital Value}

We believe that companies will pay a certain costs when hiring employees. Besides, we also need to spend some expenditure on training, education, health care and other related investment items in order to make employees give better service to our company. This part of expense together with recruitment cost forms the total cost of company's spending on employees. Employees in different positions will produce different values. A part of the values will feed back to employees themselves, while the rest of the values will return to our company. It is worth mention that the part of values returning to company should be greater than the total cost of company's paying for employees to ensure the input-output regulations, which is shown in Figure 2.

According to the mentioned above, we can obtain the relational expression below.

The return of employees + Average annual salary $=$ Human capital

For simplicity, we set $b+A s=x$ that $b>a$.

We define two rates to represent the employees' satisfaction rate and company's satisfaction rate.

$$
\alpha_{i j}=\frac{A s}{x} \quad(i=1,2,3,4,5 ; j=1,2,3,4,5,6,7),
$$




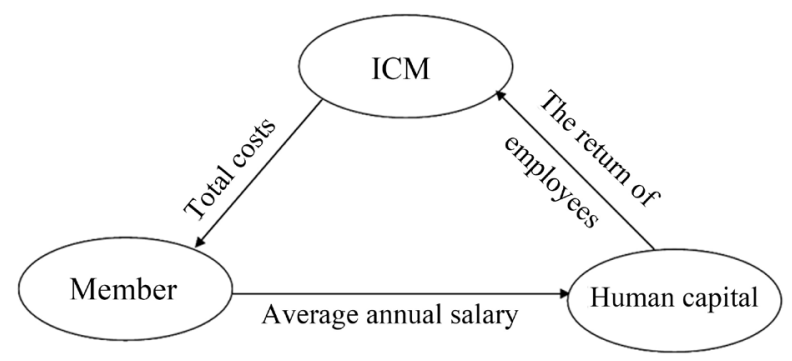

Figure 2. The allocation of human capital. Chart source: organize by the author.

Among the equation, $i$ represents the order of hierarchy, $j$ represents the order of department in the floor of $i$.

$$
\beta=\frac{b-a}{a},
$$

when employees are not satisfied with their present condition in our company, they will possibly leave the company. So, employees' satisfaction can be expressed as follows,

$$
\alpha_{i j}=1-\delta
$$

According to the relationships above, the human capital value can be expressed as follows,

$$
x=\frac{\alpha_{i j} \beta+a}{1-\alpha_{i j}} .
$$

\subsubsection{The Assumption of the Position Status of Each Department}

We assume that we have already known the position status of each department in the hierarchical structure example (rigid structure mentioned in the title) we have selected just now.

In modern society, we pursue for maximizing the work efficiency and minimize the cost of human capital investment in the enterprise, so the setting of position in each department is relatively stable. Combining with the actual business administration science, we make reasonable assumptions on the quantity of position of departments in each hierarchy of the selected branch, which is showed as Table 2 and Table 3.

We will figure out the human capital value of each department in the selected branch based on the calculation formula of the human capital value.

As for the calculation of a, we should combine with Table 1 in the title, and convert the time cost on the recruitment into opportunity cost measured by money, which can be shown as follows,

$$
a=n_{i j} \times\left(m \times \frac{A s}{12}+M c+A t\right) .
$$

\subsection{Fuzzy Synthetic Evaluation Model of Euclidean Distance's Calculation}

Fuzzy mathematics is the mathematics researching and treating with fuzziness 
Table 2. The personnel assignment of the VP branch (a).

\begin{tabular}{ccccccc}
\hline & $\begin{array}{c}\text { Senior } \\
\text { manager }\end{array}$ & $\begin{array}{c}\text { Junior } \\
\text { manager }\end{array}$ & $\begin{array}{c}\text { Experienced/ } \\
\text { Inexperienced } \\
\text { supervisor }\end{array}$ & $\begin{array}{c}\text { Experienced } \\
\text { employee }\end{array}$ & $\begin{array}{c}\text { Inexperienced } \\
\text { employee }\end{array}$ & $\begin{array}{c}\text { Administrative } \\
\text { clerk }\end{array}$ \\
\hline CEO & 1 & 0 & 0 & 0 & 0 & 3 \\
VP & 1 & 1 & 0 & 0 & 0 & 2 \\
$\begin{array}{c}\text { Program } \\
\text { Manager }\end{array}$ & 1 & 2 & 2 & 3 & 2 & 2 \\
$\begin{array}{c}\text { Production } \\
\text { Manager }\end{array}$ & 1 & 2 & 2 & 5 & 1 & 1 \\
\hline
\end{tabular}

Chart source: organize by the author.

Table 3. The personnel assignment of the VP branch (b).

\begin{tabular}{lccccc}
\hline & $\begin{array}{c}\text { Inexperienced } \\
\text { supervisor }\end{array}$ & $\begin{array}{c}\text { Experienced } \\
\text { employee }\end{array}$ & $\begin{array}{c}\text { Inexperienced } \\
\text { employee }\end{array}$ & $\begin{array}{c}\text { Inexperienced } \\
\text { employee }\end{array}$ & $\begin{array}{c}\text { Administrative } \\
\text { clerk }\end{array}$ \\
\hline Director 1 & 1 & 0 & 2 & 1 & 1 \\
Director 2 & 1 & 1 & 2 & 0 & 0 \\
Director 3 & 1 & 1 & 2 & 0 & 0 \\
Branch A & 1 & 0 & 9 & 4 & 0 \\
Branch B & 1 & 0 & 8 & 5 & 0 \\
Branch $C^{*}$ & 1 & 0 & 10 & 3 & 0 \\
Branch $D^{*}$ & 1 & 0 & 9 & 4 & 0 \\
Branch $E^{*}$ & 1 & 0 & 9 & 4 & 0 \\
Branch $F^{*}$ & 1 & 0 & 11 & 2 & 0 \\
Branch $\mathrm{F}^{*}$ & 1 & 0 & 12 & 1 & 0 \\
\hline
\end{tabular}

Chart source: organize by the author.

phenomena. With the development of the society, the problems that people research and solve by math are increasingly complex, which is hard to become precise [5]. So it's hard to research and describe the internal link between different matters by accurate math. The human capital in the enterprise management is an evaluation problem involved in the multiple factors. In addition, there will be inevitable fuzziness problem in the process of evaluation. Therefore, we should make fuzzy comprehensive evaluation of human capital value and then figure out the close degree between different departments, so that we can draw the complicated relation among various departments.

\subsubsection{Membership}

We can eliminate the subjectivity occurred in the process of evaluation and the fuzziness phenomena encountered objectively by fuzzy comprehensive evaluation. The fuzzy comprehensive evaluation is usually carried out as follows.

Establish judgment sets namely $U=\left\{u_{1}, u_{2}, u_{3}, \cdots, u_{n}\right\}$. For example, if we want to ascertain the evaluation result of human capital value, we can describe the judgment sets as $U=\{$ proximate, approximate, dis-approximate $\}$. 
We respectively describe the membership degree of each element relative to judgment sets $U$ with membership degree, and consequently reach the evaluation matrix of single factor.

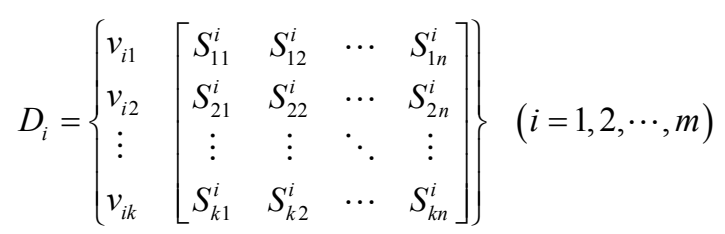

Among the evaluation matrix, $S_{i j}^{i}$ represents the first grade indicator of $i s$ second grade of $P$ s membership degree of opinion rating, $i$ represents the amount of the first grade indicator, $k$ represents the second grade's amount of the first grade of $i$ and $n$ represents the amount of judging concentration comments. The meaning and method for evaluating of $S_{l j}^{i}$ are as follows,

$$
S_{l j}^{i}=\frac{v_{i j k}}{\sum_{k=1}^{n} v_{i j k}}=\frac{v_{i j k}}{v_{i j 1}+v_{i j 2}+\cdots+v_{i j n}} .
$$

Above all, we should judge every factor and then aggregate several remarks of every sub factor $v_{i j}$ by statistics. The remarks consist of $u_{1}$ grade remark with the amount of $v_{i j 1}, u_{2}$ grade remark with the amount of $v_{i j 2}$ and $u_{n}$ grade remark with the amount of $v_{i j n}$. So the degree of sub factor floor's indicator attaching to the $u_{k}$ grade remark is membership degree. Thus the membership degree's vector quantity of the sub factor floor's indicator $v_{i j}$ is as follows,

$$
S_{l}^{i}=\left(s_{l 1}^{i}, s_{l 2}^{i}, \cdots, s_{l n}^{i}\right) \text {. }
$$

\subsubsection{First Class Fuzzy Comprehensive Evaluation}

We use fuzzy operator to ascertain fuzzy relation matrix $R=\left(R_{1}, R_{2}, \cdots, R_{n}\right)^{\mathrm{T}}$, among the matrix

$$
R_{i}=\left(w_{1}^{i}, w_{2}^{i}, \cdots, w_{k}^{i}\right)\left[\begin{array}{cccc}
S_{11}^{i} & S_{12}^{i} & \cdots & S_{1 n}^{i} \\
S_{21}^{i} & S_{22}^{i} & \cdots & S_{2 n}^{i} \\
\vdots & \vdots & \ddots & \vdots \\
S_{k 1}^{i} & S_{k 2}^{i} & \cdots & S_{k n}^{i}
\end{array}\right]=\left(r_{i 1}, r_{i 2}, \cdots, r_{i n}\right)\left(w_{1}^{i}, w_{2}^{i}, \cdots, w_{k}^{i}\right)
$$

is the ranking weight vector of the first grade indicator's subordination to the second grade indicator.

\subsubsection{The Opinion Rating of the Evaluation Object}

According to the maximum membership principle, we ascertain the opinion rating of the evaluation object.

If $e_{k}=\max \left(e_{1}, e_{2}, \cdots, e_{k}, \cdots, e_{n}\right)$, then $e_{k}$ is the vector quantity's $K$ th component. According to the maximum membership principle of fuzzy mathematics, the evaluation result of the evaluation object belongs to grade of $K$.

At last, we figure out the Euclidean distance between different grades.

$$
d_{i j}=1-\sqrt{\frac{\sum_{k}^{K}\left(a_{i k}-v_{k i}\right)^{2}}{K}} \quad(i=1,2,3,4,5 ; j=1,2,3,4,5,6,7)
$$


From the calculation of steps mentioned above, we obtain the close degree basing on the human capital value of selected various department, the tidied results is showed as Table 4.

\subsection{The VP's Branch Network of Human Capital}

We establish the fuzzy synthetic evaluation model to calculate Euclidean distance. Besides, by the programming of Pajek, we use the powerful visualization tools to build three-dimensioned reference frame. We can see it clearly as follows (Figure 3).

\section{Dynamic Complex Network Model of Human Capital}

In the first task, we have established the human capital network model. For enterprises, human capital flows into the (I), through the (II) and outflows (III) of three kinds of main forms. We can see this process in the model below (Figure 4).

In this model, the ICM and its individuals have experienced three stages all the process. ICM has the right to fire employees. Individuals also have rights to be a member of ICM. But for ICM staff, when their satisfaction is lower than a certain value, they have the right to choose to leave. At this time, the churn rate for all positions will rise. As is known to us, it is not easy to estimate the interpersonal relationship. When people leave for other jobs, other employees will be influenced. It will cause higher staff turnover rate and reduce the efficiency of organization. Therefore, human capital network can be described as a dynamic process,

Table 4. The Euclidean distance of staff offices.

\begin{tabular}{|c|c|c|c|}
\hline Staff office & Euclidean distance & Staff office & Euclidean distance \\
\hline $\begin{array}{l}\text { CEO } \\
\text { VP }\end{array}$ & 0.7265 & $\begin{array}{l}\text { Director } 1 \\
\text { Branch } A^{\star}\end{array}$ & 0.7024 \\
\hline $\begin{array}{c}\text { Program manager } \\
\text { VP }\end{array}$ & 0.8784 & $\begin{array}{l}\text { Director } 2 \\
\text { Branch } B^{\star}\end{array}$ & 0.5948 \\
\hline $\begin{array}{l}\text { Program manager } \\
\text { Production manager }\end{array}$ & 0.7963 & $\begin{array}{l}\text { Branch } A^{\star} \\
\text { Branch } B^{\star}\end{array}$ & 0.7962 \\
\hline $\begin{array}{c}\text { Program manager } \\
\text { Director } 2\end{array}$ & 0.6027 & $\begin{array}{l}\text { Branch } C^{*} \\
\text { Branch B* }\end{array}$ & 0.8793 \\
\hline $\begin{array}{c}\text { Production manager } \\
\text { Director } 1\end{array}$ & 0.6482 & $\begin{array}{l}\text { Branch } C^{*} \\
\text { Branch } D^{*}\end{array}$ & 0.8804 \\
\hline $\begin{array}{l}\text { Director } 2 \\
\text { Director } 1\end{array}$ & 0.8981 & $\begin{array}{l}\text { Branch } C^{*} \\
\text { Branch } G^{*}\end{array}$ & 0.6795 \\
\hline $\begin{array}{l}\text { Director } 2 \\
\text { Director } 3\end{array}$ & 0.8346 & $\begin{array}{l}\text { Branch } D^{*} \\
\text { Branch } G^{*}\end{array}$ & 0.7352 \\
\hline $\begin{array}{l}\text { Director } 3 \\
\text { Director } 1\end{array}$ & 0.8175 & $\begin{array}{l}\text { Branch B* } \\
\text { Branch } G^{*}\end{array}$ & 0.7196 \\
\hline
\end{tabular}

Chart source: organize by the author. 


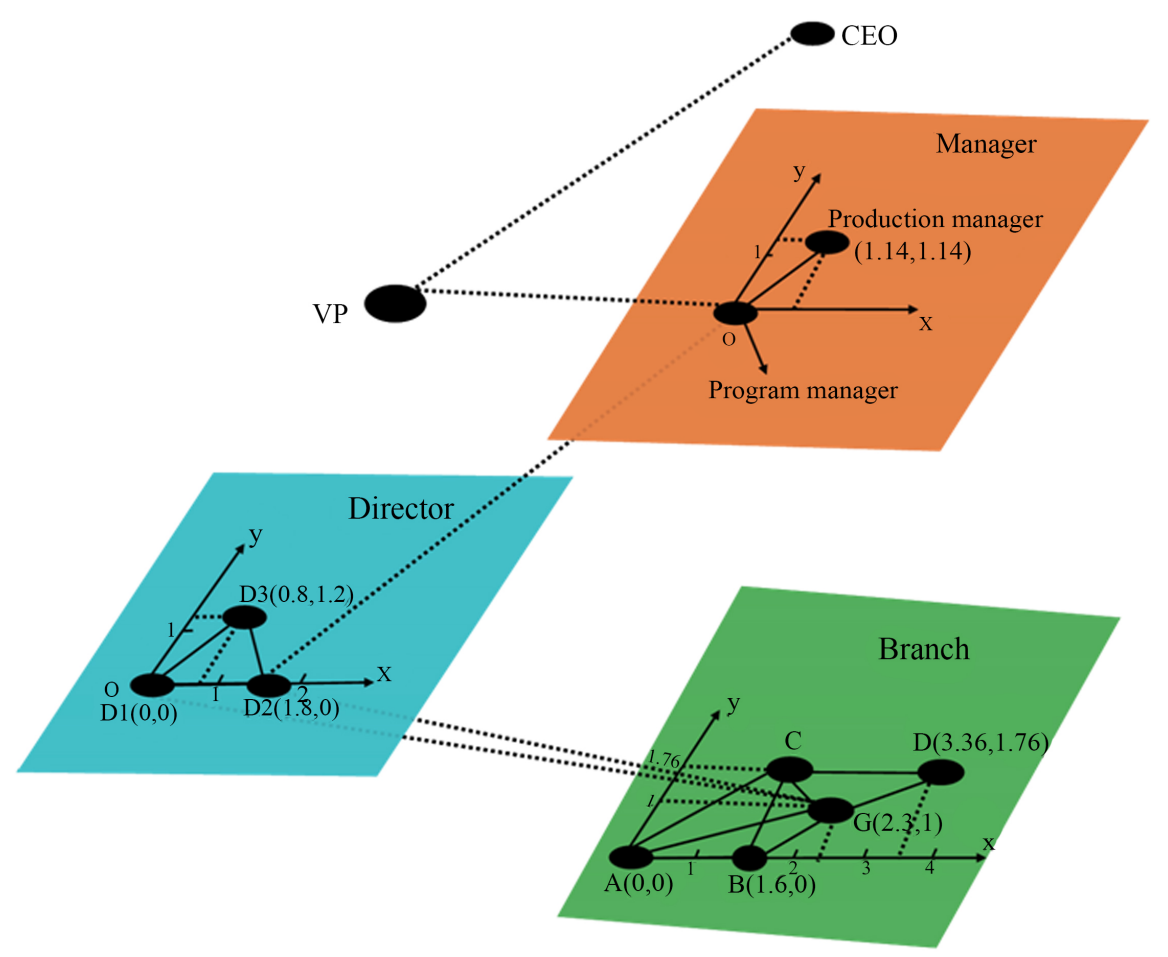

Figure 3. The VP's Branch network of human capital. Chart source: organize by the author.
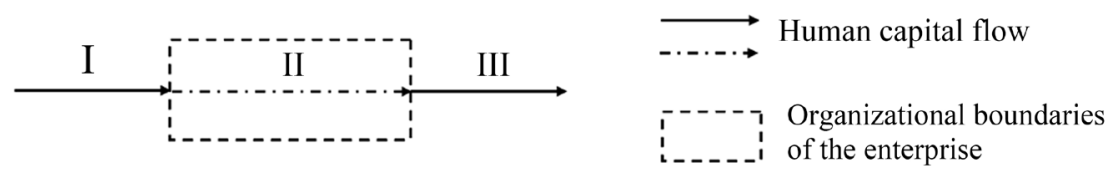

Figure 4. The human capital flow process.

we can build dynamic complex networks to study the flow of the organization, and the effects of the flow on the efficiency of organization.

\subsection{Time-Varying Complex Dynamical Network Model and Preliminaries}

In this section, we consider a complex dynamical network consisting of $N$ nonlinearly coupled different nodes, with each node being an $n_{i}$-dimensional $(i=1,2, \cdots, N)$ dynamical system [6]. The proposed time-varying dynamical network is described as,

$$
\dot{x}_{i}=f_{i}\left(x_{i}\right)+\sum_{\substack{j=1 \\ j \neq i}}^{N} c_{i j}(t) H_{i}\left(x_{i}\right)\left(\varphi_{j}\left(x_{j}\right)-\varphi_{i}\left(x_{j}\right)\right)+G_{i}\left(x_{i}\right) u_{i} \quad(i=1,2, \cdots, N)
$$

where $x_{i}=\left(x_{i 1}, x_{i 2}, \cdots, x_{i n_{i}}\right)^{\mathrm{T}} \in \mathfrak{R}^{n_{i}}, u_{i} \in \mathfrak{R}^{m}$ are the state vector and the control input of node $i$, respectively. For $i=1,2, \cdots, N, f_{i}\left(x_{i}\right) \in \mathfrak{R}^{n_{i}}$ are sufficiently smooth nonlinear vector fields, $\varphi_{i}\left(x_{i}\right): \mathfrak{R}^{n_{i}} \rightarrow \mathfrak{R}^{n_{1}}$ are sufficiently smooth nonlinear vector mappings, $H_{i}\left(x_{i}\right) \in \mathfrak{R}^{n_{i} \times n_{1}}$ and $G_{i}\left(x_{i}\right) \in \mathfrak{R}^{n_{i} \times m}$ are continuous nonlinear function matrices. Denote $C(t)=\left(c_{i j}(t)\right)_{N \times N}$ as the outer coupling 
configuration matrix (OCCM) representing the coupling strength and the topological structure of the network (1) at time $t$, in which $c_{i j}(t) \neq 0$ if there is a connection from node $i$ to node $j(j \neq i)$, otherwise $c_{i j}(t)=0(j \neq i)$, and all the coupling coefficients $c_{i j}(t)(i, j=1,2, \cdots, N)$ are bounded, that is, there exists a positive constant $\delta$ such that

$$
\left|c_{i j}(t)\right| \leq \delta,
$$

where $\delta$ is called as the coupling coefficients common bound.

Assumption 1. Consider the parameters given in the time-varying network (1). Without loss of generality, the first node is taken as the reference node. There exist $N$ state feedbacks $u_{i}=\alpha_{i}\left(x_{i}\right)+B_{i}\left(x_{i}\right) v_{i}(i=1,2, \cdots, N)$ satisfying

$$
\begin{gathered}
\frac{\partial \varphi_{i}\left(x_{i}\right)}{\partial x_{i}}\left(f_{i}\left(x_{i}\right)+G_{i}\left(x_{i}\right) \alpha_{i}\left(x_{i}\right)\right)=f_{1}\left(\varphi_{i}\left(x_{i}\right)\right)+G_{1}\left(\varphi_{i}\left(x_{i}\right)\right) \alpha_{1}\left(\varphi_{i}\left(x_{i}\right)\right) \\
\frac{\partial \varphi_{i}\left(x_{i}\right)}{\partial x_{i}} G_{i}\left(x_{i}\right) B_{i}\left(x_{i}\right)=G_{1}\left(\varphi_{i}\left(x_{i}\right)\right) B_{1}\left(\varphi_{i}\left(x_{i}\right)\right),
\end{gathered}
$$

where

$$
\frac{\partial \varphi_{i}\left(x_{i}\right)}{\partial x_{i}}=\left(\frac{\partial \varphi_{i k}\left(x_{i}\right)}{\partial x_{i j}}\right)_{n_{1} \times n_{i}}\left(j=1,2, \cdots, n_{i} ; k=1,2, \cdots, n_{1}\right)
$$

is the Jacobi matrix with dimension $n_{1} \times n_{i}, \alpha_{i}\left(x_{i}\right)$ are $m$-dimensional smooth nonlinear mappings and $B_{i}\left(x_{i}\right)$ are $m \times m$ invertible smooth nonlinear function matrices.

Remark 1. It is not difficult to find the state-feedback controllers $u_{i}=\alpha_{i}\left(x_{i}\right)+B_{i}\left(x_{i}\right) v_{i}$ satisfying (3) and (4). Firstly, for the given $\varphi_{i}\left(x_{i}\right)$ and $G_{i}\left(x_{i}\right)$, and the invertibility of $B_{i}\left(x_{i}\right)$ and $B_{1}\left(\varphi_{i}\left(x_{i}\right)\right)$, we can find the compatible $B_{i}\left(x_{i}\right) ; B_{1}\left(\varphi_{i}\left(x_{i}\right)\right)$ and $G_{i}\left(\varphi_{i}\left(x_{i}\right)\right)$ satisfying (3). Then, substituting $G_{i}\left(\varphi_{i}\left(x_{i}\right)\right)$ into (4), the suitable $\alpha_{i}\left(x_{i}\right)$ and $\alpha_{i}\left(\varphi_{i}\left(x_{i}\right)\right)$ can be obtained. In general, many controllers $u_{i}$ can satisfy (3) and (4).

\subsection{Exponential Synchronization for the Time-Varying Network}

In real-world networks, although it is often difficult to obtain the exact information about coupling coefficients, it is easy to get the coupling coefficients common bound. Hence, the objective of this section is to synthesize appropriate decentralized state-feedback controllers $u_{i}(i=1,2, \cdots, N)$ for network (1), which guarantee the network (1) can realize exponential synchronization [7].

For simplicity, denote $y_{i}=\varphi_{i}\left(x_{i}\right)$ and the synchronous errors between node $i$ and node $j$ be as follows,

$$
e_{i j}=\varphi_{i}\left(x_{i}\right)-\varphi_{j}\left(x_{j}\right)=y_{i}-y_{j}(i, j=1,2, \cdots, N) .
$$

Assumption 1. The coupling coefficients common bound is available, that is, the parameter $\delta$ in (2) is known.

The time-varying complex dynamical network (1) can achieve global exponential synchronization with the following decentralized state-feedback control- 
lers,

$$
\begin{gathered}
u_{i}=\alpha_{i}\left(x_{i}\right)+B_{i}\left(x_{i}\right) v_{i}, \\
v_{i}=\left(B_{1}\left(\varphi_{i}\left(x_{i}\right)\right)\right)^{-1}\left[-\alpha_{1}\left(\varphi_{i}\left(x_{i}\right)\right)-(2 k \delta+\eta)\left(G_{1 R}\left(\varphi_{i}\left(x_{i}\right)\right)\right)^{-1} \varphi_{i}\left(x_{i}\right)\right] .
\end{gathered}
$$

where $i=1,2, \cdots, N, k, \eta \in \mathfrak{R}$ are both designing positive constants.

Proof. For simplicity, notice that $e_{i i}=\varphi_{i}\left(x_{i}\right)-\varphi_{i}\left(x_{i}\right)=0$. We can get the error dynamics for the networks (1) with controllers (5) and (7) as follows.

$$
\begin{aligned}
\dot{e}_{i j}= & \frac{\partial \varphi_{i}\left(x_{i}\right)}{\partial x_{i}} \dot{x}_{i}-\frac{\partial \varphi_{j}\left(x_{j}\right)}{\partial x_{j}} \dot{x}_{j} \\
= & \frac{\partial \varphi_{i}\left(x_{i}\right)}{\partial x_{i}}\left[f_{i}\left(x_{i}\right)+G_{i}\left(x_{i}\right) \alpha_{i}\left(x_{i}\right)+G_{i}\left(x_{i}\right) B_{i}\left(x_{i}\right) v_{i}+\delta \sum_{j=1}^{N} c_{i j} H_{i}\left(x_{i}\right) \varphi_{j}\left(x_{j}\right)\right] \\
& -\frac{\partial \varphi_{j}\left(x_{j}\right)}{\partial x_{j}}\left(f_{1}(s)+\delta \sum_{j=1}^{N} c_{i j} \tilde{H}_{j}\left(x_{j}\right) s+G_{j}\left(x_{j}\right) \alpha_{i}\left(x_{i}\right)+G_{i}\left(x_{i}\right) B_{i}\left(x_{i}\right) v_{i}\right) \\
= & f_{1}\left(\varphi_{i}\left(x_{i}\right)\right)+g_{1}\left(\varphi_{i}\left(x_{i}\right)\right)\left(\alpha_{1}\left(\varphi_{i}\left(x_{i}\right)\right)+\beta_{1}\left(\varphi_{i}\left(x_{i}\right)\right) v_{i}\right) \\
& -f_{1}(s)+\delta \sum_{j=1}^{N} c_{i j} \tilde{H}_{i}\left(x_{i}\right)\left(\varphi_{j}\left(x_{j}\right)-s\right) \\
= & f_{1}\left(\varphi_{i}\left(x_{i}\right)\right)-f_{1}(s)+d_{i} g_{1}\left(\varphi_{i}\left(x_{i}\right)\right) g_{1}^{\mathrm{T}}\left(\varphi_{i}\left(x_{i}\right)\right) e_{i}+\delta \sum_{j=1}^{N} c_{i j} \tilde{H}_{i}\left(x_{i}\right) e_{j} .
\end{aligned}
$$

where $i, j=1,2, \cdots, N$.

Choose the Lyapunov functional candidate as,

$$
V=\sum_{i=1}^{N}\left(\frac{e_{i}^{\mathrm{T}} e_{i}}{2}+\frac{\left(d_{i}+d\right)^{2}}{2 k_{i}}\right) .
$$

Then, with Equation (8), the time derivative of $V(t)$ along the trajectories of error dynamics (9) is

$$
\begin{aligned}
\dot{V}= & \sum_{i=1}^{N} e_{i}^{\mathrm{T}} \dot{e}_{i}+\sum_{i=1}^{N} \frac{\left(d_{i}+d\right)}{k_{i}} \dot{d}_{i} \\
\leq & \mu \sum_{i=1}^{N} e_{i}^{\mathrm{T}} e_{i}-d \sum_{i=1}^{N} e_{i}^{\mathrm{T}} g_{1}\left(\varphi_{i}\left(x_{i}\right)\right) g_{1}^{\mathrm{T}}\left(\varphi_{i}\left(x_{i}\right)\right) e_{i} \\
& +\delta \sum_{i=1}^{N} \sum_{j=1}^{N} \frac{e_{i}^{\mathrm{T}} \tilde{H}_{i}\left(x_{i}\right) \tilde{H}_{i}^{\mathrm{T}}\left(x_{i}\right) e_{i}+c_{i j}^{2} e_{j}^{\mathrm{T}} e_{j}}{2} \\
\leq & \sum_{i=1}^{N} e_{i}^{\mathrm{T}}\left[\left(\mu+\frac{\delta \tilde{c}}{2}\right) I_{n 1}-d g_{1}\left(\varphi_{i}\left(x_{i}\right)\right) g_{1}^{\mathrm{T}}\left(\varphi_{i}\left(x_{i}\right)\right)+\frac{\delta N}{2} \tilde{H}_{i}\left(x_{i}\right) \tilde{H}_{i}^{\mathrm{T}}\left(x_{i}\right)\right] e_{i}
\end{aligned}
$$

According to Equation (5) and Equation (10), it can be deduced that $\dot{V}<0$.

\subsection{Numerical Example}

The Hindmarsh-Rose (HR) dynamical system is a well-known model of neuronal activity [8], which can exhibit rich firing behaviors [7]. In what follows, we consider a network with $\mathrm{N}=10$ different-dimensional HR neurons, where the dynamics of each uncontrolled isolated node is as follows, 


$$
\dot{x}_{1}=f_{1}\left(x_{1}\right)=\left[\begin{array}{c}
a\left(x_{12}-x_{11}\right) \\
-x_{11} x_{13}+c_{1} x_{12} \\
x_{11} x_{12}-b x_{13}
\end{array}\right], \quad \dot{x}_{i}=f_{i}\left(x_{i}\right)=\left[\begin{array}{c}
a\left(x_{i 2}-x_{i 1}\right)+x_{i 4} \\
-x_{i 1} x_{i 3}+c_{2} x_{i 2} \\
x_{i 1} x_{i 2}-b x_{i 3} \\
x_{i 1} x_{i 3}+d x_{i 4} \\
\arctan x_{i 5} \\
\vdots \\
\arctan x_{i, i+2}
\end{array}\right] \text {. }
$$

where $a, b, c, d$ are the constant parameters that govern the dynamics of the neural system. The variable $x_{i 1}$ is a voltage associated to the membrane potential, variable $x_{i 2}$ although in principle associated to a recovery current of factions has dimensions of voltage, variable $x_{i 3}$ is a slow adaptation current associated to slow ions, variable $x_{i 4}$ represents an even slower process than $x_{i 3}$ variable, respectively.

In order to estimate costs reasonably, we consider hired employees as inflow of human capital in the dynamic network. Then, we allocate the recruitment of personnel according to the original proportion of the various positions. The churn rate of ICM is $18 \%$. Owing to the time-varying complex dynamical network model and exponential synchronization model, the organization's recruitment rate is $8.6 \%$. Combined with the organization of the ICM position configuration status, we can get the recruitment of staff situation as follows.

Combined with Table 1 and Table 5, we can calculate ICM recruitment and training budgets of $34.22 \sigma$.

\section{Dynamic Simulation Model of the Staff Turnover}

\subsection{Assumption and Reasonable Explanation of the Model}

- There will be job vacancy due to the employee turnover. Under the circumstances, ICM prefers to recruit new staff whose professional ability is similar with the ones leaving the company from the outside in order to keep the service behavior of work group in ICM as steady as possible.

\section{Explanation}

Staff turnover of every enterprise is inevitable and the loss of staff is bound to bring job vacancies. There are usually two methods to fill the job vacancy, external recruitment and promotion of internal employees. The external recruitment has the advantage of being able to hire experienced employees in given position, so that the new employees can involve themselves in this position quickly.

Meanwhile, the department's schedule can also operate normally according to

Table 5. The number of staff recruitment.

\begin{tabular}{ccccccc}
\hline $\begin{array}{c}\text { Level of } \\
\text { position }\end{array}$ & $\begin{array}{c}\text { Senior } \\
\text { manager }\end{array}$ & $\begin{array}{c}\text { Junior } \\
\text { manager }\end{array}$ & $\begin{array}{c}\text { Experienced/ } \\
\text { Inexperienced } \\
\text { supervisor }\end{array}$ & $\begin{array}{c}\text { Experienced } \\
\text { employee }\end{array}$ & $\begin{array}{c}\text { Inexperienced Administrative } \\
\text { employee }\end{array}$ & clerk \\
\hline Quantity & 1 & 2 & 4 & 10 & 12 & 3 \\
\hline
\end{tabular}


the previous work pace. But we will take some risks if we promote internal cadres. Because the internal promoted employees are usually inexperienced in a new position and whether he can reach the work efficiency of previous employee or not is unknown. Only from work efficiency's point of view, it will reduce the work efficiency of the departments and increase the risk of turnover to replace the vacant position with internal promoted employees.

Based on the assumption mentioned above, the integrity of the staff is only related to staff turnover rate named $v$ and hiring rate named $\mu$.

\subsection{The Specific of Full Status for Positions}

On the basis of human capital's dynamic complex network model, we use the visualization tools of Pajek to make analogue simulation on selected research object's human capital flow condition [9].

\subsubsection{The Simulation Result When the Changing Rate Is $25 \%$}

We study whether the research object can maintain position integrity of $80 \%$ when the churn rate of the employees reaches $25 \%$.

We let the changing churn rate be $25 \%$. Owing to the time-varying complex dynamical network model, we can know the recruitment rate $\mu=10.31 \%$ at this moment. Next, we let the position's integrity degree of $80 \%$ be a screened threshold value $\delta$, and we can get the emulation results as Figure 5 shows.

In Figure 5, the green points represent the departments that can pass the threshold value. In other words, these parts can maintain the degree of position integrity above $80 \%$ on the condition that churn rate is $25 \%$. The red points represent the departments that can't pass the threshold value. That is to say, these

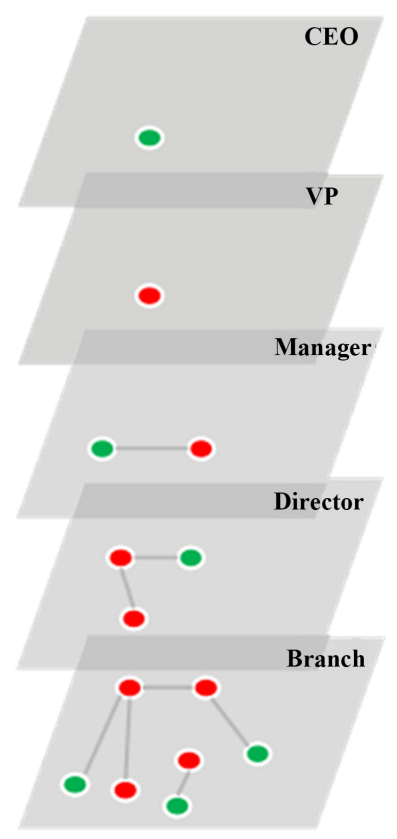

Figure 5. The overall situation of department when staff turnover rate is $25 \%$. Chart source: organize by the author. 
parts can't maintain the degree of position integrity above $80 \%$ when the churn rate is $25 \%$.

From Figure 5, we can reach the research object's condition of position integrity when the churn rate is $25 \%$, which is shown as Table 6 .

\subsubsection{The Simulation Result When the Changing Rate Is 35\%}

We study whether the research object can maintain position integrity of $80 \%$ when the changing churn rate of the employees is $35 \%$.

When the changing churn rate is $35 \%$, according to the time-varying complex dynamical network model, we can know the recruitment rate $\mu=14.66 \%$. Besides, we let threshold value $\delta$ be $80 \%$. By the visualization tools of Pajek, we get the emulation results as Figure 6 shows.

In a similar way, we can reach the research object's condition of position integrity when the churn rate is $35 \%$, which is showed as Table 7 .

Compared with Table 6, the research object can almost not maintain its position integrity of $80 \%$ when the churn rate is $35 \%$. We can see that the degree of position integrity is lower with the higher churn rate of human capital. At such a high churn rate of employees of $35 \%$, most of the departments of ICM can't guarantee its degree of position integrity above $80 \%$, in which case we may think the human resource condition of ICM is very unhealthy at this moment.

\subsubsection{The Bad Influence of High Staff Changing Churn Rate on Enterprise} From above analysis, the high staff churn rate is of great harm to an enterprise and has a direct effect on the following points:

1) Affecting the staff morale of ICM. The departure of an employee will affect

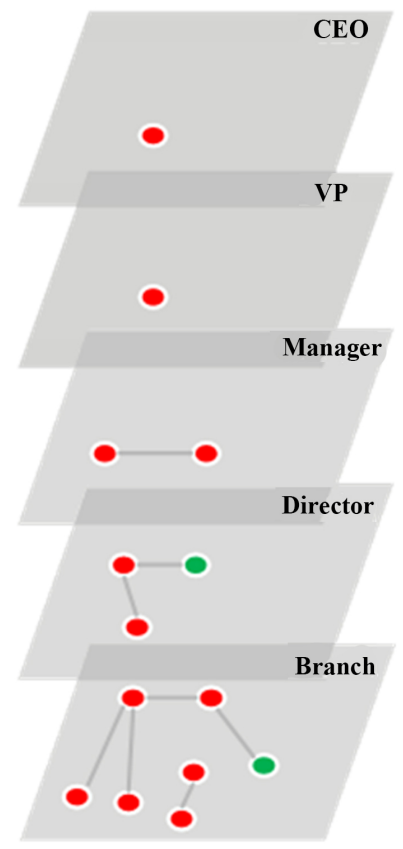

Figure 6. The overall situation of department when staff turnover rate is $35 \%$. Chart source: organize by the author. 
Table 6. The overall situation of department when staff turnover rate is $25 \%$.

Over 80\% CEO, Program manager, Director 1, Director 3, Branch B, Branch C, Branch E, Branch F

Under 80\% VP, Production manager, Director 2, Branch A, Branch D, Branch G

Chart source: organize by the author.

Table 7. The overall situation of department when staff turnover rate is $35 \%$.

\begin{tabular}{ll}
\hline Over $80 \%$ & Director 2, Branch G \\
Under $80 \%$ & $\begin{array}{l}\text { CEO, VP, Production manager, Program manager, Director 1, Director 2, Branch A to } \\
\text { Branch F }\end{array}$ \\
\hline
\end{tabular}

Chart source: organize by the author.

the morale of several employees because the departed one tends to make negative remarks about the enterprise in public.

2) Increasing the operating costs of ICM. With the departure of the former employees, there must be some new employees needed, which will invisibly increase the recruitment costs and training costs. At the same time the efficiency and job performance of newcomers are low, which makes the operating costs high all the time.

3) Influencing the team efficiency of ICM. Human resource shortages caused by employee churn will directly affect the team efficiency of ICM.

4) Affecting the long-term development of ICM. High rate of staff churn will certainly lead to a decline in the overall level of enterprise's talent, and consequently lead to the decline of enterprises' competitiveness. And the decline of the enterprise's competitiveness is bound to affect the long-term development of the enterprise.

\subsection{The Direct and Indirect Costs of High Turnover Rate}

The high churn rate of staff will certainly bring a high rate of staff turnover and the high turnover rate is bound to increase the cost of human resources. So we can roughly divide this costs into direct costs and indirect costs:

\subsubsection{Direct Costs of High Turnover Rate}

1) Recruitment costs mainly include: the preparation, screening resumes, interviewing costs, the cost of preparation for hiring and handling the recruitment procedures etc.

2) Training costs mainly include: pre-post training preparation, training materials, training management costs etc.

3) Costs that internal staff to fill job vacancies mainly include: the cost of internal staff to fill job vacancies, additional overtime working costs, the costs that executives coordinate to complete the work etc.

4) Costs during the new employees adapting to the position. When employees come to a new position, there must be an adjustment period. And in this period, the enterprise still needs to pay wages, which undoubtedly increases the enterprise's costs. 


\subsubsection{Indirect Costs of High Turnover Rate}

1) Costs caused by the flagging morale. The departure of one staff will make the other staff to leave the company like domino. What's more there will be a process of consideration before they leave the job. During the process, employees will inevitably look for colleagues to discuss and naturally affect the emotion of other employees, which will reduce the efficiency of team cooperation.

2) Costs caused by the lack of reserve forces of enterprise. The frequent staff churn makes it difficult to select the middle managers because of the lack of talents, thereby making the enterprise unable to fill the middle-level position vacancies inside if they select senior personnel from the mid-level position, which will cause a shortage of talent. Eventually it will influence the echelon building of enterprise.

3) Costs caused by the leaks of important secrets. These important secrets are about technology, loss of customer resources, the re-use of management methods etc.

\section{The Simulation Model of ICM's Staff Flow}

\subsection{Assumption and Reasonable Explanation of the Model}

- Due to the employee turnover, ICM fill the job vacancy only by promoting internal employees without external recruitment.

For this assumption, we try to consider ICM as a completely closed system and there is the output but no input of the human capital in this system. So we can better research and analyze the flow condition of internal human resources in ICM.

- The internal promotion of ICM is in strict accordance with rigid structure of position, that is to say, the position of the upper hierarchy can only be replaced by the position of lower hierarchy just adjacent to the upper one, and there is no Great promotion.

As we all know, the condition of the Great promotion is relatively rare in reality. There are certain obstacles among hierarchical structures of enterprise. The obstacles can be divided into ability obstacle, experience obstacle and communication. The bigger the hierarchical span is, the more obviously the obstacles perform, which is the objective law existed in enterprise management. Therefore the assumption is relatively close to reality.

For example, the vacant position, senior manager can only be replaced by the lower position or experienced supervisor. In addition, when the employee turnover occurs, the vacant position will be soon filled with personnel qualified to promote. This process doesn't cost any time and it continues until no second-string employees can be promoted.

\subsection{The Simulation Model of Integrity Degree for Junior Managers}

\subsubsection{The Status Quo of ICM}

ICM is now facing a serious problem. ICM recognizes that middle managers (ju- 
nior managers, experienced supervisors, inexperienced supervisors) often feel stuck in their jobs with little opportunity to advance, causing them to leave the company when they find a comparable or better job. These mid-level positions are critical ones that unfortunately suffer high turn-over (twice the average rate of the rest of the company) and seem to need filling all the time. This is the main cause of high churn rate and lower recruitment rate of middle managers at present. Hence we select 5 junior managers and 15 experienced supervisors as object to research.

\subsubsection{The Display of ICM Staff's Flow Simulation Results}

On the basis of human capital's dynamic complex network model, we use the visualization tools of Pajek to make analogue simulation of the next two years' flow condition on 5 junior managers and 15 experienced supervisors of the research objects. In this way, we make simulation of changing condition during the two years on 5 junior managers of research objects. First, we set the churn rate as $30 \%$. Based on the assumptions above, we can know that the present recruitment rate is 0 . Second, we set the threshold value (the integrity rate of the bottom employees) as $85 \%, 70 \%$ and $50 \%$, respectively. And then through the simulation by Pajek, we get the results as Figure 7 shows.

In Figure 7, the red point means that the position is vacant in the $i$ th year. If we only consider the employee promotion, then there is no one qualified to fill the position. The green point means that there is someone in the position of the $i$ th year.

\subsection{The Simulation Model of Integrity Degree for Experienced Supervisors}

In a similar way, we make simulation of changing condition during the two years on 15 experienced supervisors of research objects. First, we set the churn rate as $30 \%$. On the base of the assumptions above, we can know that the present recruitment rate is 0 . Second, we set the threshold value as $85 \%, 70 \%$ and $50 \%$, respectively. And then through the simulation of the visualization tools of Pajek, we get the results as Figure 8 shows.

\subsection{The Summary of These Two Simulation Models}

We sort out the results of Figure 7 and Figure 8, and consequently get the Table 8 and Table 9.

From the Figure 7, we can obtain the position's integrity condition of research object named junior managers in different position's integrity degree, which is shown in Table 8.

From the Figure 7, in a similar way, the position's integrity condition of research object named experienced supervisor has been got. We can see it in Table 9.

Under normal conditions, ICM usually has $85 \%$ of its 370 positions filled at any time. So we may think it is healthy when the position's integrity degree of 


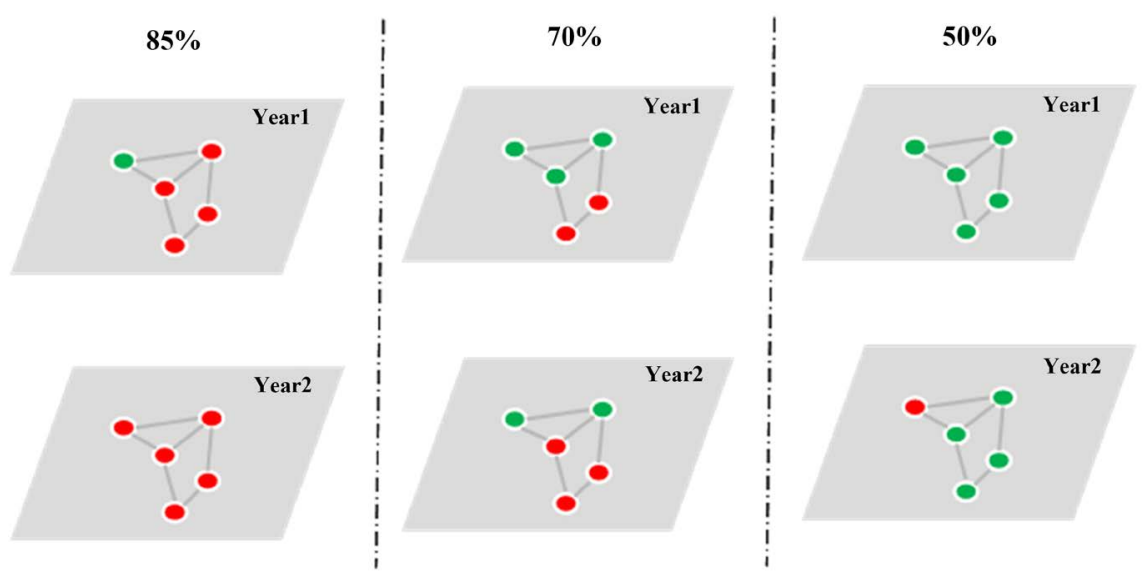

Figure 7. The full status for positions of junior manager. Chart source: organize by the author.
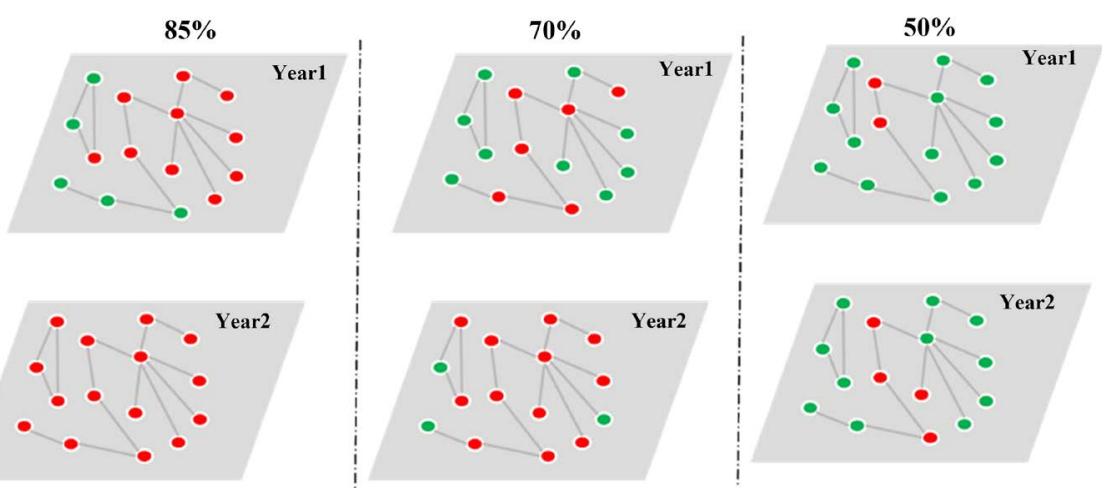

Figure 8. The full status for positions of experienced supervisors. Chart source: organize by the author.

Table 8. The full status for positions of junior manager.

\begin{tabular}{llll}
\hline & $85 \%$ & $70 \%$ & $50 \%$ \\
\hline Year 1 & $20 \%$ & $60 \%$ & Full \\
Year 2 & Null & $40 \%$ & $80 \%$
\end{tabular}

Chart source: organize by the author.

Table 9. The full status for positions of experienced supervisor.

\begin{tabular}{cccc}
\hline & $85 \%$ & $70 \%$ & $50 \%$ \\
\hline Year 1 & $33.3 \%$ & $60 \%$ & $86.7 \%$ \\
Year 2 & Null & $13.3 \%$ & $73.3 \%$ \\
\hline
\end{tabular}

Chart source: organize by the author.

research object is above $85 \%$. However, from the results we can see that when the churn rate reaches $30 \%$, the selected research object is difficult to reach healthy condition even the integrity rate of the bottom employees is merely kept at the lever of $50 \%$. At last, we draw the conclusion that at the churn rate of $30 \%$, the human resource organization is in an unealthy condition of constant employee 
turnover without recruitment from the outside.

\section{Testing the Model}

According to the calculation formula of human capital, the value of human capital can be expressed as the following form,

$$
x=\frac{(1-\delta) \beta+n_{i j} \times\left(m \times \frac{A s}{12}+M c+A t\right)}{\delta} .
$$

Aiming at each factor of the formula, we study the effect on human capital value when these factors change in the same ratio while the other factors keep unchanged. For easy figures, we set each factor's changing ratio as the same values of $10 \%$. And the each factor's raw value of the formula is set as follows,

$$
\delta=80 \%, \beta=70 \%, n_{i j}=4, m=6, A s=4 \sigma, M c=0.7 \sigma, A t=0.6 \sigma .
$$

\subsection{The Sensitivity Index of Churn Rate of the Employees to the Human Capital Value}

The changing churn rate of the employees is $\delta^{\prime}=\delta \times(1+10 \%)$.

The changing human capital value is

$$
x^{\prime}=\frac{\left(1-\delta^{\prime}\right) \beta+n_{i j} \times\left(m \times \frac{A s}{12}+M c+A t\right)}{\delta^{\prime}} .
$$

The changing ratio of human capital value is $\lambda_{1}=\frac{x^{\prime}-x}{x}$.

So, the sensitivity index of churn rate of the employees to the human capital value is $\eta_{1}=\frac{\lambda_{1}}{10 \%}$.

We calculate and simplify the equation, drawing that

$$
\eta_{1}=\frac{-\left[\beta+n_{i j} \times\left(m \times \frac{A s}{12}+M c+A t\right)\right]}{1.1 \beta \times(1-\delta)+1.1 n_{i j} \times\left(m \times \frac{A s}{12}+M c+A t\right)}
$$

Substituting the given data into calculation, we can draw that

$$
\eta_{1}=-\frac{7+132 \sigma}{1.54+145.2 \sigma} \times 100 \%
$$

\subsection{The Sensitivity Index of the Satisfaction Rate}

The changing satisfaction rate of the company is $\beta^{\prime}=\beta \times(1+10 \%)$.

The changing human capital value is

$$
x^{\prime}=\frac{(1-\delta) \beta^{\prime}+n_{i j} \times\left(m \times \frac{A s}{12}+M c+A t\right)}{\delta} .
$$

The changing ratio of human capital value is $\lambda_{2}=\frac{x^{\prime}-x}{x}$. 
So, the sensitivity index of the satisfaction rate value is $\eta_{2}=\frac{\lambda_{2}}{10 \%}$.

We calculate and simplify the equation, drawing that $\eta_{2}=\frac{1.4}{1.4+132 \sigma} \times 100 \%$.

\subsection{The Sensitivity Index of the Other Five Factors}

In a similar way, we can obtain that the sensitivity index of the amount of employees of each hierarchy to the human capital value

$$
\eta_{3}=\frac{4488 \sigma}{1.4+132 \sigma} \times 100 \% .
$$

The sensitivity index of median time to recruit (months) to the human capital value is

$$
\eta_{4}=\frac{80 \sigma}{1.4+132 \sigma} \times 100 \% .
$$

The sensitivity index of employees' average annual salary rate for given lever to the human capital value is

$$
\eta_{5}=\frac{80 \sigma}{1.4+132 \sigma} \times 100 \% .
$$

The sensitivity index of median cost of recruitment to the human capital value is

$$
\eta_{6}=\frac{28 \sigma}{1.4+132 \sigma} \times 100 \% .
$$

The sensitivity index of average annual training cost to the human capital value is

$$
\eta_{7}=\frac{24 \sigma}{1.4+132 \sigma} \times 100 \%
$$

\subsection{The Comparison of the Sensitivity Index's Absolute Value}

Comparing their absolute value, we can obtain that

$$
\eta_{3} \gg\left|\eta_{1}\right|>\eta_{4}=\eta_{5}>\eta_{6}>\eta_{7} \gg \eta_{2} .
$$

That is to say, the amount of employees of each hierarchy has greatest influence on human capital value, while the satisfaction rate of the company has the least influence. Besides, the median time to recruit has the same influence as employees' average annual salary rate on human capital value. It's clear that the sensitivity index of churn rate of the employees is a negative number. But the other factors' sensitivity indexes are all positive number. It suggests that the increase of employees' churn rate will reduce the human capital value. However, the other factors' influence on the human capital is positive.

In combination with the results above, we can draw the conclusion that: to maximize the human capital value, we should mainly focus on distribution of every lever's quantity of employees carefully. What's more, we should also try to 
reduce company's churn rate of the employees, allocate the recruiting time and employees' average annual salary rate reasonably, and plan recruitment costs as well as employees' average annual salary rate properly. To achieve the required goal of human capital value, we can make the same change on the recruitment time or the employees' average annual salary rate.

\section{Final Conclusion}

Through setting up the dynamic complex network model of human capital, the author draw the conclusion that the next two years' budget of recruiting and training is $34.22 \sigma$ when the annual churn rate goes to $18 \%$. Through establishing the dynamic simulation model of the staff turnover, the author reached the position's integrity condition of ICM when the job churn rate is $25 \%$ and $35 \%$, respectively.

Then the author explained the costs caused by high turnover rates and the indirect effects of high churn rates. The author simulated the change of position's integrity degree of junior managers and experienced supervisors in the next two years. The author concluded that the HR health of the organization is below the expectation.

In addition, the author made sensitivity analysis on the 7 factors of human capital value and consequently drew that the amount of employees of each hierarchy has the greatest influence on human capital value.

\section{Limitations and Further Discussion of the Model}

How to connect our Human Capital network with other layers of organizational network such as information flow, trust, influence and friendship?

We have an idea.

We know that different employees have different relationships in ICM. This kind of relationship can be formatted, on the base of several levels such as information flow, trust, influence and friendship etc. As the human resources department of ICM, we have the ability to collect the interpersonal networks at different levels and we can let each employee provide their personal networks at different levels, whose form is shown in Figure 9.

Figure 9 shows the relationships of an employee in ICM at different levels such as information flow, trust, influence and friendship [4].

By analyzing the interpersonal relationship plate at different levels provided by each employee, we can aggregate the relationships among all the employees in ICM so that we get the interpersonal networks at every level of the whole ICM, as is shown in Figure 10.

In Figure 10, different colors of board represent the interpersonal networks at different levels of all employees [4]. At each level such as friendship, we assume that the employee 1 has contact with the employee 2 so we link this two with a solid line. At different levels such as the friendship and trust, we assume that the employee 1 and the employee 2 have a relation in the friendship. In the trust level, 


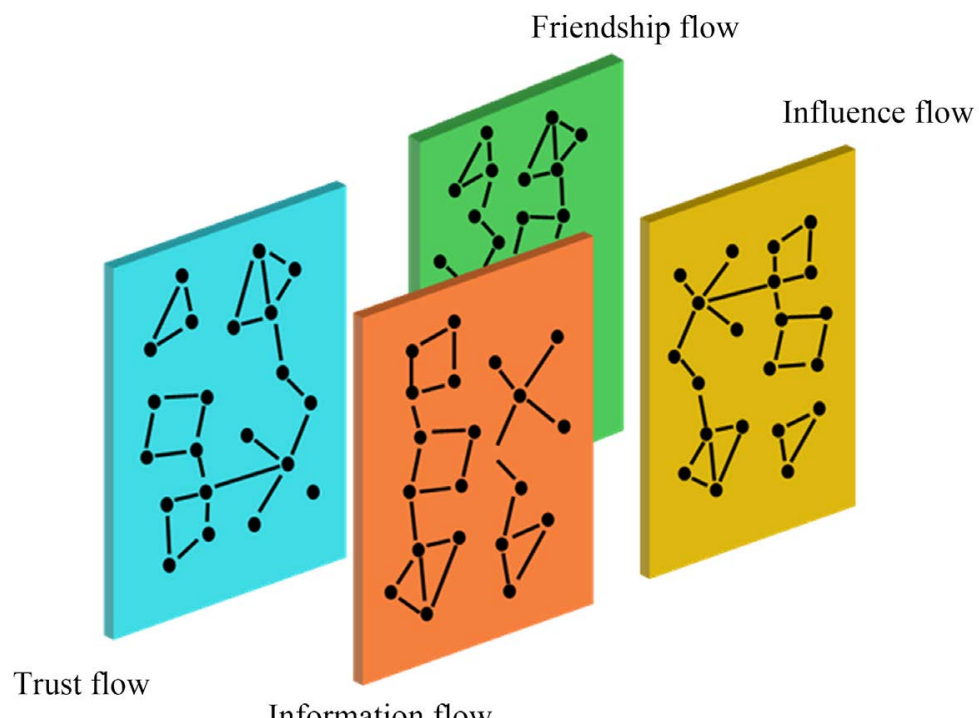

Figure 9. The personal networks at four main levels. Chart source: organize by the author.
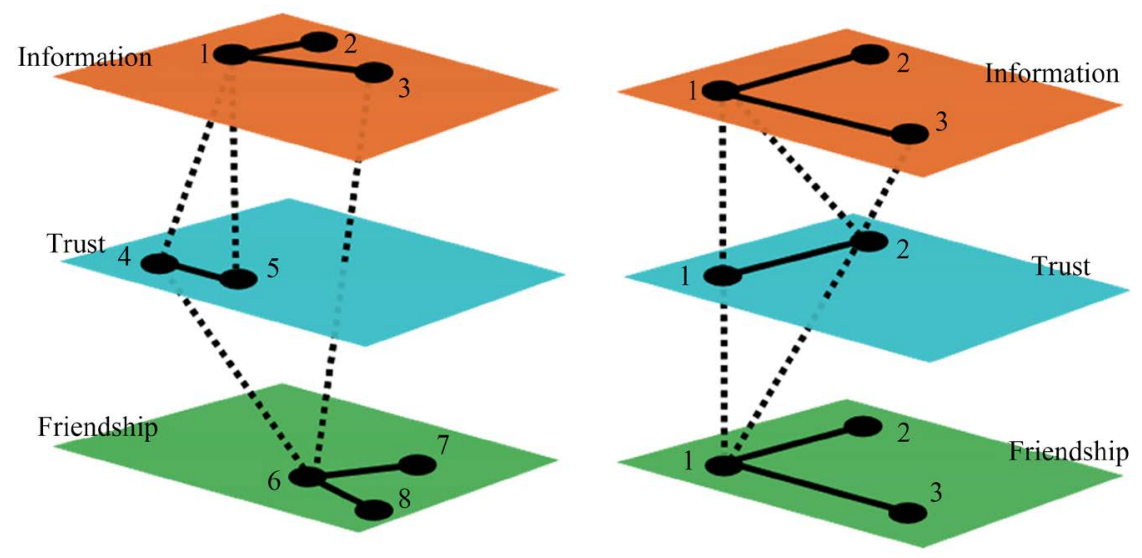

Figure 10. The personal networks at four main levels. Chart source: organize by the author

the employee 1 still has connection with the employee 2. Under such circumstances, we will link the employee 1 and the employee 2 at different levels with a dotted line. Thus we can get a three-dimensional interpersonal relationship network of all employees in ICM at different levels. By doing this, not only can we clearly see the interpersonal relationships among employees at each level, but we can also observe the interpersonal relationships of all the staff in ICM at different levels from the three-dimensional point of view.

But the model the author built is lack of practicality to some extent especially when facing different companies and organizations. The author didn't have enough consideration for organizational diversity.

However, the author can define that the solid line represents strong relation while the dotted line link represents weak relation. When the staff turnover occurs, it is bound to have an impact on interpersonal relationship network related 
to him. How it affects the others? The effect is strong or weak? We can all analyze these problems by the network.

\section{Conflicts of Interest}

The author declares no conflicts of interest regarding the publication of this paper.

\section{References}

[1] Martins, T.V., et al. (2009) Network Effects in a Human Capital Based Economic Growth Model. Physica A, 388, 2207-2214.

https://doi.org/10.1016/j.physa.2009.02.006

[2] Pozzi, F., Bottino, R.M. and Persico, D. (2014) Enhancing Human Capital in TEL Research: A Case Study from the STELLAR Network of Excellence. Computers in Human Behavior, 31, 425-431. https://doi.org/10.1016/j.chb.2013.10.062

[3] Fagan, J. and Ployhart, R.E. (2015) The Information Processing Foundations of Human Capital Resources: Leveraging Insights from Information Processing Approaches to Intelligence. Human Resource Management Review, 25, 4-11. https://doi.org/10.1016/j.hrmr.2014.09.003

[4] Kivela, M., Arenas, A., Barthelemy, M., Gleeson, J.P., Moreno, Y. and Porter, M.A. (2013) Multilayer Networks. Journal of Complex Networks, 2, 203-271. https://doi.org/10.1093/comnet/cnu016

[5] Wu, D.T. and Li, D.F. (2004) Shortcomings of Analytical Hierarchy Process and the Path to Improve the Method. Journal of Beijing Normal University (Natural Science), 40, 265-267.

[6] Zhang, L.L., Wang, Y.H. and Wang, Q.Y. (2015) Synchronization for Time-Varying Complex Dynamical Networks with Different-Dimensional Nodes and Non-Dissipative Coupling. Communications in Nonlinear Science and Numerical Simulation, 24, 64-74. https://doi.org/10.1016/j.cnsns.2014.12.012

[7] Zhang, L.L., Wang, Y.H., Wang, Q.Y., Wang, Q.R. and Zhang, Y. (2013) Synchronisation of Complex Dynamical Networks with Dynamics of Nodes via Decentralised Dynamical Compensation Conrollers. International Journal of Control, 86, 1766-1776. https://doi.org/10.1080/00207179.2013.796525

[8] Hrg, D. (2013) Synchronization of Two Hindmarsh-Rose Neurons with Unidirectional Coupling. Neural Networks, 40, 73-79. https://doi.org/10.1016/j.neunet.2012.12.010

[9] de Nooy, W., Mrvar, A. and Batagelj, V. Exploratory Social Network Analysis with Pajek. https://www.docin.com/p-1774451668.html 